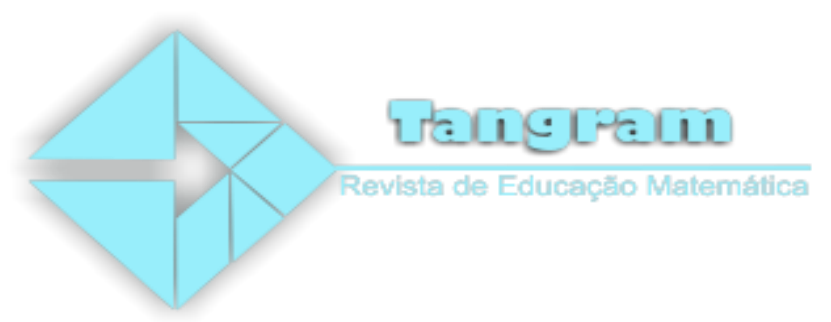

\title{
Trigonometria e suas aplicações no Geogebra: aulas experimentais com alunos do ensino médio
}

\section{Trigonometry and its applications in Geogebra: experimental classes with high school students}

\author{
Italândia Ferreira de Azevedo ${ }^{1}$ \\ Francisco Régis Vieira Alves ${ }^{2}$
}

Resumo: Este artigo apresenta um relato de experiência que consistiu na realização de duas aulas práticas envolvendo o ensino de trigonometria e o uso do software Geogebra em uma turma de $2^{\circ}$ ano do Ensino Médio de uma escola profissional do norte do Ceará. As práticas tiveram o intuito de revisar e aprofundar os conceitos matemáticos a partir da construção e resolução de problemas por meio do software Geogebra. A realização aconteceu no laboratório de informática da escola durante o horário de aula, por meio de aulas experimentais, onde os alunos tiveram a oportunidade de desenvolver seus conhecimentos criativos e autônomos a partir do software. Por fim, a experiência foi fundamental para adquirir e ampliar técnicas de ensino, desenvolvendo habilidades que exigem mais do que uma aula tradicional de matemática.

Palavras-chave: Ensino de matemática. Geogebra. Trigonometria.

\begin{abstract}
This article presents an experience report that consisted in the accomplishment of two practical classes involving the teaching of Trigonometry and the use of Geogebra software in a class of 2nd year of the High School of a professional school of the north of Ceará. The practices were designed to review and deepen the mathematical concepts from the construction and resolution of problems through Geogebra software. The realization took place in the computer lab of the school during the class hours, through experimental classes, where the students had the opportunity to develop their creative and autonomous knowledge from the software. Finally, experience was instrumental in acquiring and expanding teaching techniques, developing skills that require more than a traditional Mathematics class.
\end{abstract}

Keywords: Mathematics teaching. Geogebra. Trigonometry.

\footnotetext{
${ }^{1}$ Instituto Federal de Educação do Ceará

${ }^{2}$ Instituto Federal de Educação do Ceará. Doutor em ênfase no ensino de Matemática (UFC - 2011)

Tangram - Revista de Educação Matemática, Dourados - MS - v.2 n. 2, pp. 102 - 115 (2019)
} 


\section{Trigonometria e suas aplicações no Geogebra: aulas experimentais com alunos do ensino médio}

\section{Introdução}

As novas tecnologias estão surgindo de uma forma rápida e inovadora, a busca por novas alternativas de ensino pelos profissionais da educação constitui um processo educativo desafiador. Toledo (2015) afirma que com as novas tecnologias computacionais o professor pode desenvolver nos alunos o raciocínio lógico e a consciência crítica.

Então, para subsidiar os docentes da educação básica quanto ao uso de recursos tecnológicos para o ensino da matemática, pesquisadores em educação matemática, a exemplo Alves (2014), Lisboa (2013), Pacheco e Barros (2012), discutem tendências metodológicas (resolução de problemas e tecnologias digitais) para o ensino de matemática.

Dentre as tendências citadas, destacamos o uso de tecnologias digitais, pelo fato de possibilitar, a partir dos softwares educativos, uma transposição didática e conhecimento prático, envolvendo manipulação pelo próprio aluno, cálculos mentais e criatividade no ato de resolver uma situação-problema.

A partir daí se configura a necessidade de inserir essas tecnologias digitais nos espaços escolares, permitindo uma relação mais atrativa do ensino e aprendizagem entre professor - aluno - conhecimento, já que essas tecnologias estão cada vez mais presentes no cotidiano de nossos alunos. Com o uso dos softwares educativos foi observado que algumas habilidades, como a atenção, concentração, ritmo, percepção visual e auditiva podem ser estimuladas nos alunos (Lisboa, 2013). Além disso, Alves (2014, p. 10) afirma que os softwares podem tornar mais acessível "o contato com certos objetos, propriedades e teoremas que, via de regra, exigiriam um tempo bem maior de estudo de certas teorias formais".

A partir dessa afirmação, observamos a necessidade do uso de um recurso digital para o ensino de trigonometria, o qual é considerado bastante abstrato por muitos alunos, por ser ensinado sem nenhuma aplicação prática, baseado apenas na transmissão de fórmulas e regras, não apresentando nenhum significado para a maioria dos alunos (Maia; Pereira, 2015).

Assim, no âmbito desse contexto, este trabalho teve como objetivo geral apresentar uma atividade desenvolvida no laboratório de informática para o ensino de trigonometria, com intuito de revisar e aprofundar os conceitos matemáticos a partir da construção e resolução de problemas por meio do software Geogebra. Os principais objetivos específicos Tangram - Revista de Educação Matemática, Dourados - MS - v.2 n. 2, pp. 102-115 (2019) 


\section{Trigonometria e suas aplicações no Geogebra: aulas experimentais com alunos do ensino médio}

foram: rever os assuntos de ciclo trigonométrico e funções trigonométricas de forma prática e lúdica; apresentar o software Geogebra como ferramenta de aprendizagem; construir o ciclo trigonométrico e função seno realizando seus estudos.

A partir desse recurso digital, pretendemos mostrar que é possível ensinar trigonometria de forma prazerosa e que o Geogebra se apresenta como um meio facilitador nesse elo de conhecimento matemático.

\section{Os softwares como recursos pedagógicos}

As Tecnologias de Comunicação e Informação (TIC) são segundo Bohn (2011) apud Castilho (2015, p. 33), “o resultado da fusão das telecomunicações, da informática, e das mídias eletrônicas e servem de ferramentas mediadoras do processo educacional como um todo". Atualmente essas tecnologias estão cada vez mais presentes na sala de aula e no cotidiano dos alunos, tornando-se num instrumento importante para a educação.

Os softwares educacionais têm como proposta dar suporte ao processo de ensinoaprendizagem nas diversas áreas de ensino. "Nesse processo, pode ser uma ferramenta extremamente útil, em que o aluno se torna um ser ativo na construção do conhecimento, direcionado pelo professor" (Toledo, 2015, p. 31).

Segundo Gladcheff, Zuffi e Silva (2001) apud Pacheco e Barros (2012) os softwares educativos nas aulas de matemática podem consentir diversos objetivos: ser fonte de informação, auxiliar o processo de construção de conhecimentos, ampliar a autonomia do raciocínio, da reflexão e da criação de soluções.

Pacheco e Barros (2012) afirmam que através do computador e do software, o aluno poderá fazer uma ponte entre os conceitos matemáticos e o mundo prático. Assim, o uso do software educativo pode auxiliar na transmissão da informação, quebrando a dinâmica tradicional do ensino da matemática, ou seja, deixando o aprendizado mais atraente.

De acordo com Lisboa (2013, p. 13 ), “[...] para que as tecnologias digitais tenham eficácia como recurso didático se faz necessário que os educadores conheçam os softwares educativos e suas possibilidades". O professor necessita conhecer essa ferramenta pedagógica com mais detalhes e aprofundamento, sendo ainda um grande desafio para os educadores que atuam em todos os níveis de ensino se adaptarem com tantas tecnologias. Tangram - Revista de Educação Matemática, Dourados - MS - v.2 n. 2, pp. 102-115 (2019) 


\section{Trigonometria e suas aplicações no Geogebra: aulas experimentais com alunos do ensino médio}

Agora relacionando o processo de aprendizagem, o aluno precisa identificar no software um aliado na busca do seu conhecimento.

Os softwares matemáticos podem ser grandes aliados nas aulas de Matemática, mas é necessário um bom planejamento do professor para que estes se tornem um importante aliado no processo de ensino e aprendizagem e que o aluno tenha clareza de que a sua utilização é importante dentro do processo de aprendizagem. (Maia; Pereira, 2015, p. 403)

A escolha do software depende dos objetivos que o professor deseja alcançar com o conteúdo, necessitando de um planejamento que busque e almeje sempre a aprendizagem do aluno. É preciso também que o professor saiba manusear e conhecer suas ferramentas, caso contrário, não há sentido apresentar uma aula informatizada.

\section{O geogebra e o ensino de trigonometria}

O Geogebra é um software gratuito desenvolvido para a educação matemática, onde reúne assuntos como: Geometria, Álgebra e Cálculo, podendo ser trabalhado no ensino e aprendizagem da matemática em qualquer nível ou modalidade. É considerado um software de Geometria Dinâmica por vários autores, a exemplo Lopes (2011), Costa e Souza (2011) e Costa (2017).

Para Lopes (2011) uma característica do software de Geometria Dinâmica é possibilitar o movimento dos objetos na tela, possibilitando investigações, descobertas, confirmações de resultados, simulações e permite levantar questões relacionadas com a sua aplicação prática.

Reforçando essas ideias Costa e Souza (2011) enfatizam que em um ambiente de geometria dinâmica como o Geogebra, tem uma atuação positiva na construção do conhecimento por parte dos alunos, bem como permite ações interpretativas de situações problemas.

Tangram - Revista de Educação Matemática, Dourados - MS - v.2 n. 2, pp. 102-115 (2019) 


\section{Trigonometria e suas aplicações no Geogebra: aulas experimentais com alunos do ensino médio}

Nessa perspectiva, as atividades propostas nas oficinas através da resolução de problemas, focaram-se de modo que o aluno fosse o construtor e atuante em ações interpretativo-desafiadoras, afim de que refletissem sobre os resultados obtidos e chegando às conclusões autônomas, bastando ao professor/estagiário a mediação desse processo de ensino e aprendizagem. (Costa; Souza, 2011, p. 35)

Costa (2017, p. 60) defende que o software Geogebra funciona como uma ferramenta de ensino, permitindo "potencializar a compreensão de propriedades de determinadas figuras que permanecem invariantes nas construções geométricas dinâmicas". A autora fala também sobre a utilização do ambiente dinâmico e a importância de desenvolvermos nos alunos a capacidade de resolver questões.

A utilização do ambiente de geometria dinâmica [...] é uma ação que favorece as construções geométricas, trigonométricas e gráficas, mas é fundamental que os alunos compreendam e expressem o seu raciocínio lógico-dedutivo na resolução das questões. (Costa, 2017, p. 106)

Como exposto anteriormente, um ambiente de geometria dinâmica facilita nas construções trigonométricas. Então, por que não ensinar trigonometria com o auxílio do Geogebra? Geralmente esse conteúdo não é bem aceito pelos alunos, devido as dificuldades inerentes ao estudo do caráter periódico de suas funções e de suas várias manipulações algébricas.

Assim, cabe ao professor utilizar meios para que a assimilação deste conteúdo seja significativa e que o ensino deva estar relacionado com aplicações do dia a dia, fazendo uso de recursos que possam estimular os alunos a compreendê-los (Magalhães, 2018).

\section{Descrição das atividades práticas}

A pesquisa de investigação desse trabalho foi considerada qualitativa, devido ter ênfase voltada para as observações da professora e participação dos alunos nas práticas e entrevistas, sendo possível a coleta de dados empíricos.

O presente relato de experiência reporta ao trabalho desenvolvido em 2016 na turma do $2^{\circ}$ ano do curso técnico em fabricação mecânica da EEEP Prof ${ }^{a}$ Lysia Pimentel Gomes Tangram - Revista de Educação Matemática, Dourados - MS - v.2 n. 2, pp. 102-115 (2019) 


\section{Trigonometria e suas aplicações no Geogebra: aulas experimentais com alunos do ensino médio}

Sampaio Sales, situada na cidade de Sobral-CE. A turma era composta por 29 alunos com faixa etária entre 16 e 17 anos. O que motivou a escolha desta turma foi o fato de que a maioria dos alunos apresentavam desmotivação e deficiência em alguns conteúdos de matemática, principalmente no assunto de trigonometria, sendo bastante cobrado em avaliações externas e primordial para o andamento do curso técnico em mecânica.

A partir dessa situação, a professora de matemática planejou duas aulas práticas de trigonometria, partindo de situações das quais os alunos pudessem participar da construção desse conhecimento. Segundo Maia e Pereira (2015, p. 402), “tentando assim, desfazer a antipatia que boa parte dos estudantes tem pelo ensino da Matemática e, de modo especial, pela trigonometria”. Com base nessa reflexão, procurou-se expandir esse assunto usando recursos digitais que auxiliassem a aula de matemática e proporcionassem uma aprendizagem mais significativa. O software GeoGebra foi usado como suporte pedagógico para abordar o conteúdo de uma forma prática e atraente para os alunos.

As práticas ou aulas experimentais aconteceram em duas aulas no laboratório de matemática da escola com duração de 50 minutos. O laboratório tem um acervo de apenas 10 computadores, com isso a turma foi dividida em duplas e trios, para Lisboa (2013) a ideia é criar o hábito de realizar tarefas em duplas ou grupos para que se auxiliem.

$\mathrm{Na}$ primeira aula experimental realizamos a explanação do conteúdo de trigonometria, apresentando as aplicações das funções trigonométricas no cotidiano e fazendo alguns questionamentos do tipo: onde podemos aplicar a trigonometria? Quais as profissões que podem usar esse conhecimento? Qual a importância de ser aprender trigonometria? Antes de iniciar a prática no GeoGebra, foi apresentado o vídeo3 "Tutorial GeoGebra - parte I", onde mostra os recursos disponíveis e o que se pode utilizar no software.

Em seguida, apresentamos o Geogebra de forma prática, permitindo os alunos realizarem suas próprias explanações e conhecerem as funcionalidades de suas ferramentas. Seguimos, construindo o passo a passo do ciclo trigonométrico (Figura 1), onde acrescentamos a medida do comprimento, do ângulo e arco da circunferência.

3 Vídeo: Tutorial GeoGebra - parte I. Disponível em: https://www.youtube.com/watch?v=x-fJy6vRNXE

Tangram - Revista de Educação Matemática, Dourados - MS - v.2 n. 2, pp. 102-115 (2019) 


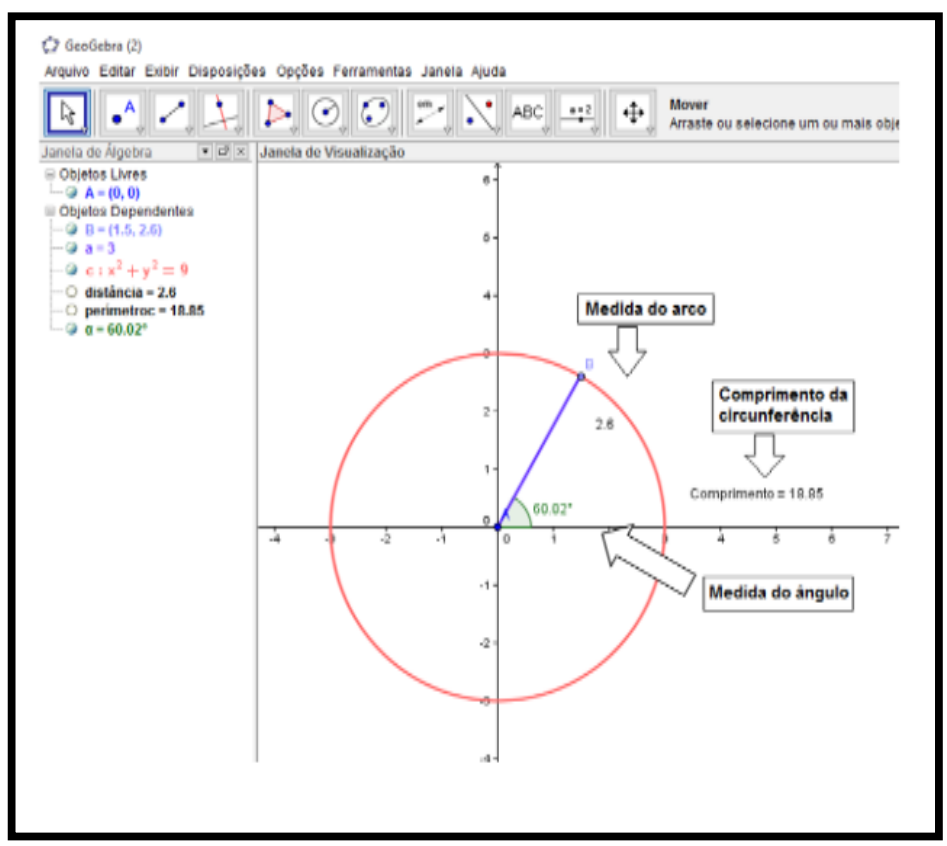

Figura 1 - Construção do Ciclo Trigonométrico. Fonte: Construído pela professora.

Posteriormente, os alunos construíram o ciclo trigonométrico (Figura 2 e 3 ) usando as ferramentas apresentadas inicialmente pela professora. Observamos que algumas duplas aperfeiçoaram suas construções colocando preenchimento e modificando o estilo do raio, deixando a entender que os alunos já buscavam novas aprendizagem de forma autônoma para aperfeiçoar suas construções.

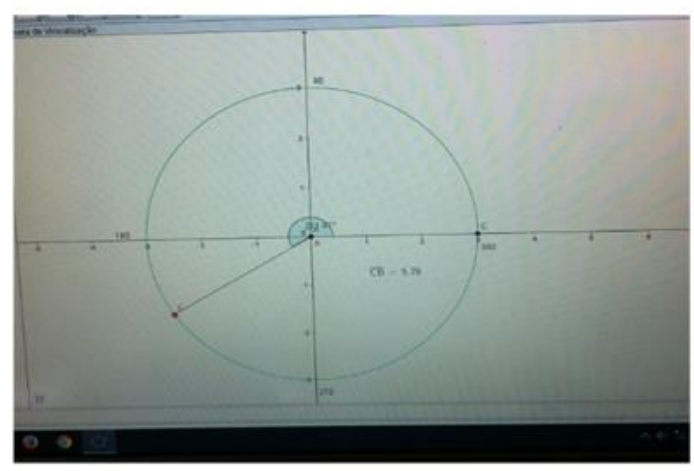

Figura 2 - Construção do Ciclo

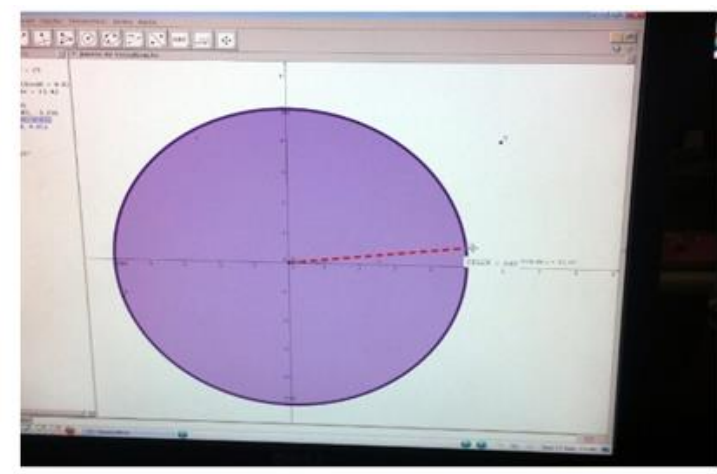

Figura 3 - Construção do Ciclo

Fonte: Construído pelos alunos.

Tangram - Revista de Educação Matemática, Dourados - MS - v.2 n. 2, pp. 102-115 (2019) 


\section{Trigonometria e suas aplicações no Geogebra: aulas experimentais com alunos do ensino médio}

Continuamos a aula, realizando as construções dos gráficos da função polinomial de primeiro grau e função quadrática, para posteriormente, iniciarmos a revisão das funções trigonométricas. Analisamos os comportamentos dos gráficos fazendo observação para o domínio, imagem, ponto máximo e mínimo, função crescente e decrescente, encerrando com o zero da função.

Nas figuras 4 e 5 encontramos as construções das funções: $f(x)=2 x$ e $f(x)=x^{2}+2 x-1$ realizadas pelos alunos. A partir da demonstração do estudo dos comportamentos dos gráficos apresentado anteriormente pelos professores, os alunos realizaram esse estudo fazendo observações com sua dupla ou trio e realizando anotações no caderno.

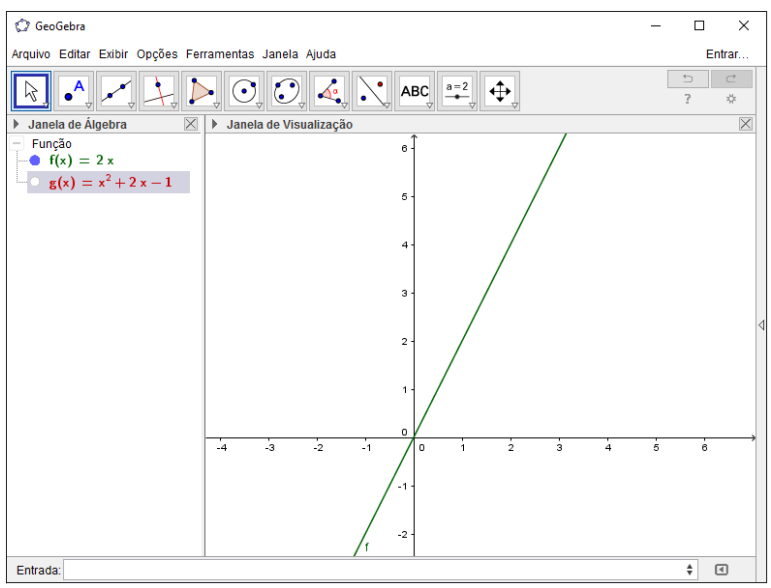

Figura 4 - Construção do gráfico da função

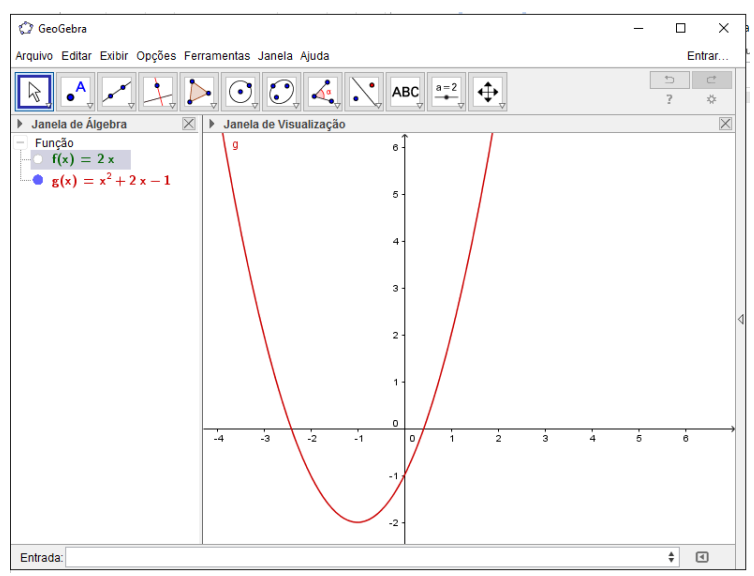

Figura 5- Construção do gráfico da função

Fonte: Construído pelos alunos.

Na segunda aula experimental, seguimos com a revisão das funções trigonométricas do seno e cosseno e suas aplicabilidades no cotidiano. Porém, devido ao pouco tempo, aprofundamo-nos somente ao estudo do comportamento da função seno.

Os alunos construíram as funções: $\boldsymbol{f}(\boldsymbol{x})=\operatorname{sen} \boldsymbol{x} \boldsymbol{e} \boldsymbol{g}(\boldsymbol{x})=\boldsymbol{c o s} \boldsymbol{x}$ (Figura 6 e 7) e realizaram o estudo de seus comportamentos, usaram a oralidade e a escrita para concluírem suas análises sobre os gráficos. 
Trigonometria e suas aplicações no Geogebra: aulas experimentais com alunos do ensino médio

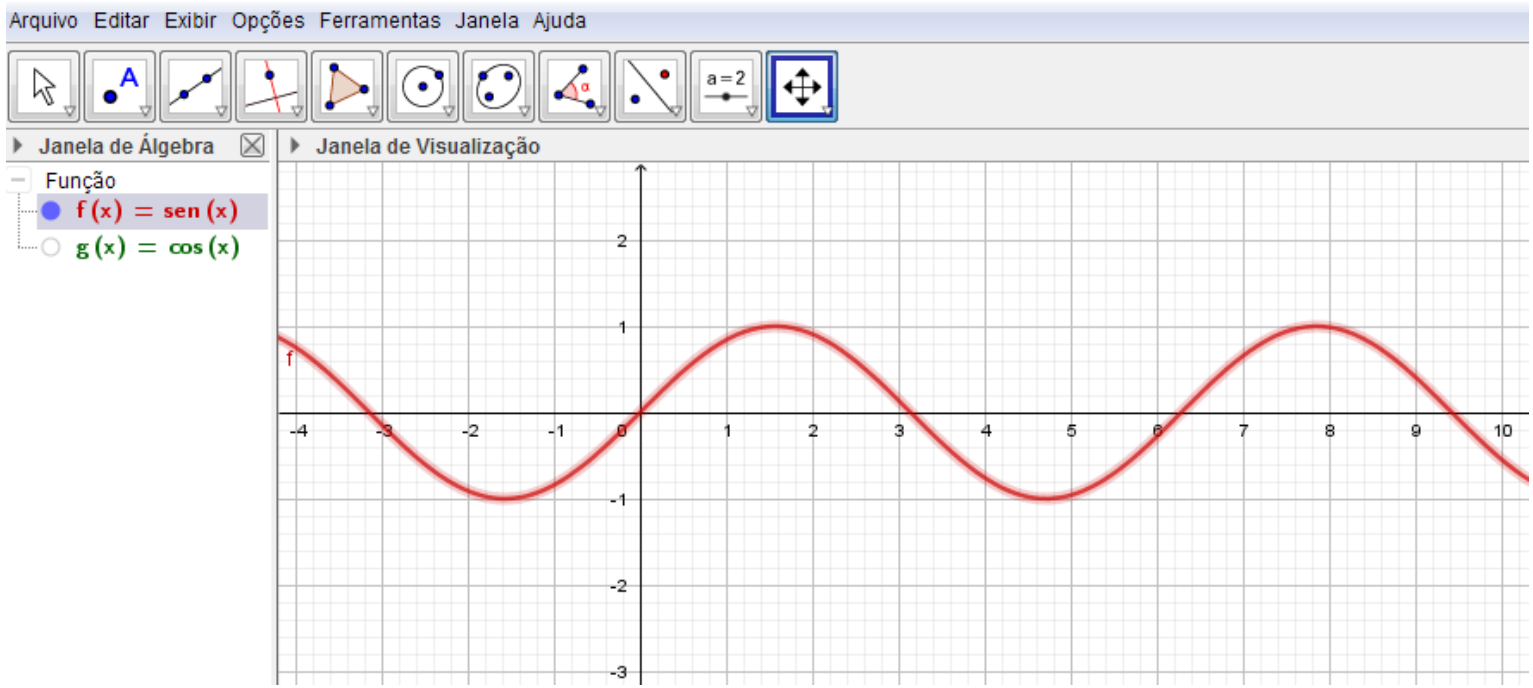

Figura 6 - Construção do gráfico da função seno: $\mathrm{f}(\mathrm{x})=$ sen $\mathrm{x}$. Fonte: Construção da autora.

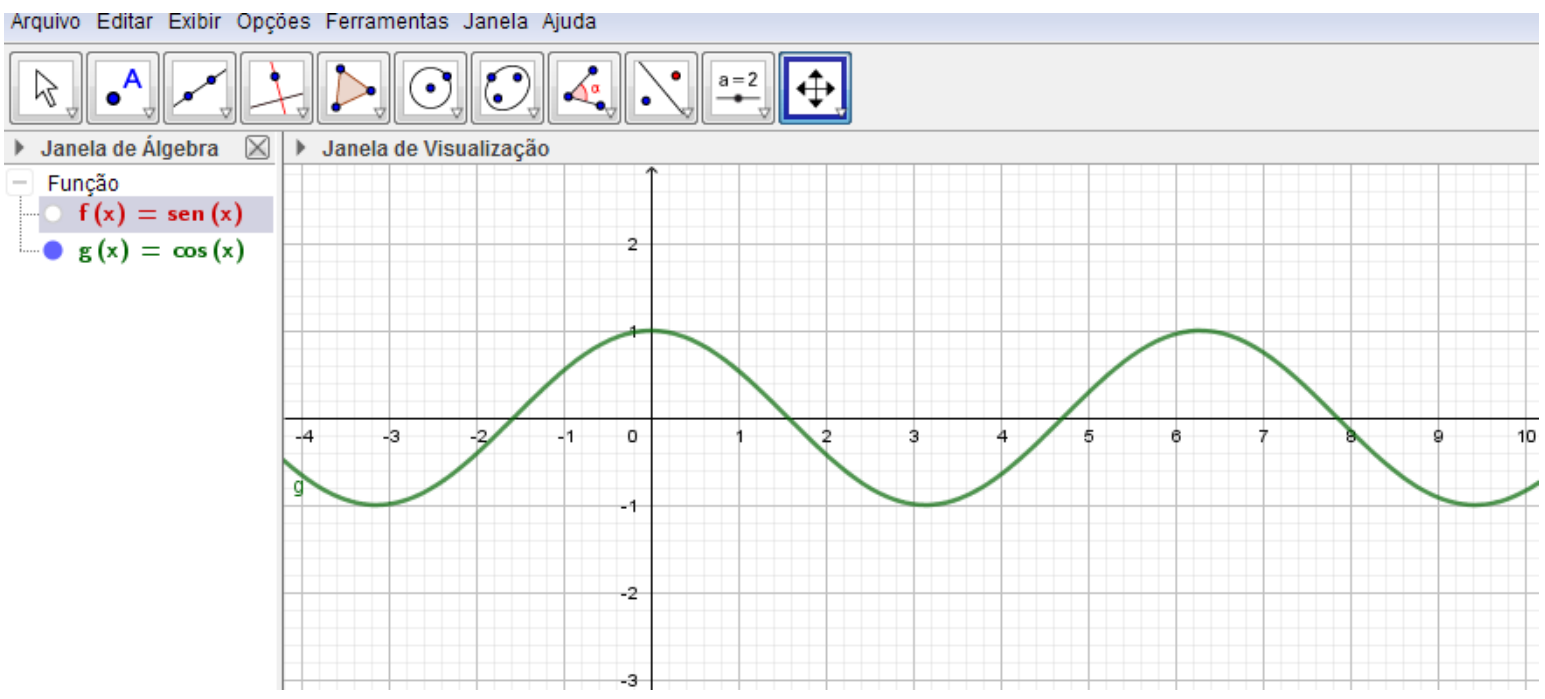

Figura 7 - Construção do gráfico da função cosseno: $\mathrm{g}(\mathrm{x})=\cos \mathrm{x}$.

Fonte: Construção da autora.

Em seguida, para obtermos o avanço e aprofundamento no conteúdo da função seno, propusemos as seguintes construções: a) $\boldsymbol{h}(\boldsymbol{x})=\operatorname{sen} \boldsymbol{x}, b) \boldsymbol{p}(\boldsymbol{x})=2 \operatorname{sen} \boldsymbol{x}$, c) $\boldsymbol{p}(\boldsymbol{x})=3 \operatorname{sen} \boldsymbol{x}, d$ ) $p(x)=5 \operatorname{sen} x$.

Os gráficos plotados nessa atividade se encontram na figura 8 .

Tangram - Revista de Educação Matemática, Dourados - MS - v.2 n. 2, pp. 102-115 (2019) 


\section{Trigonometria e suas aplicações no Geogebra: aulas experimentais com alunos do ensino médio}

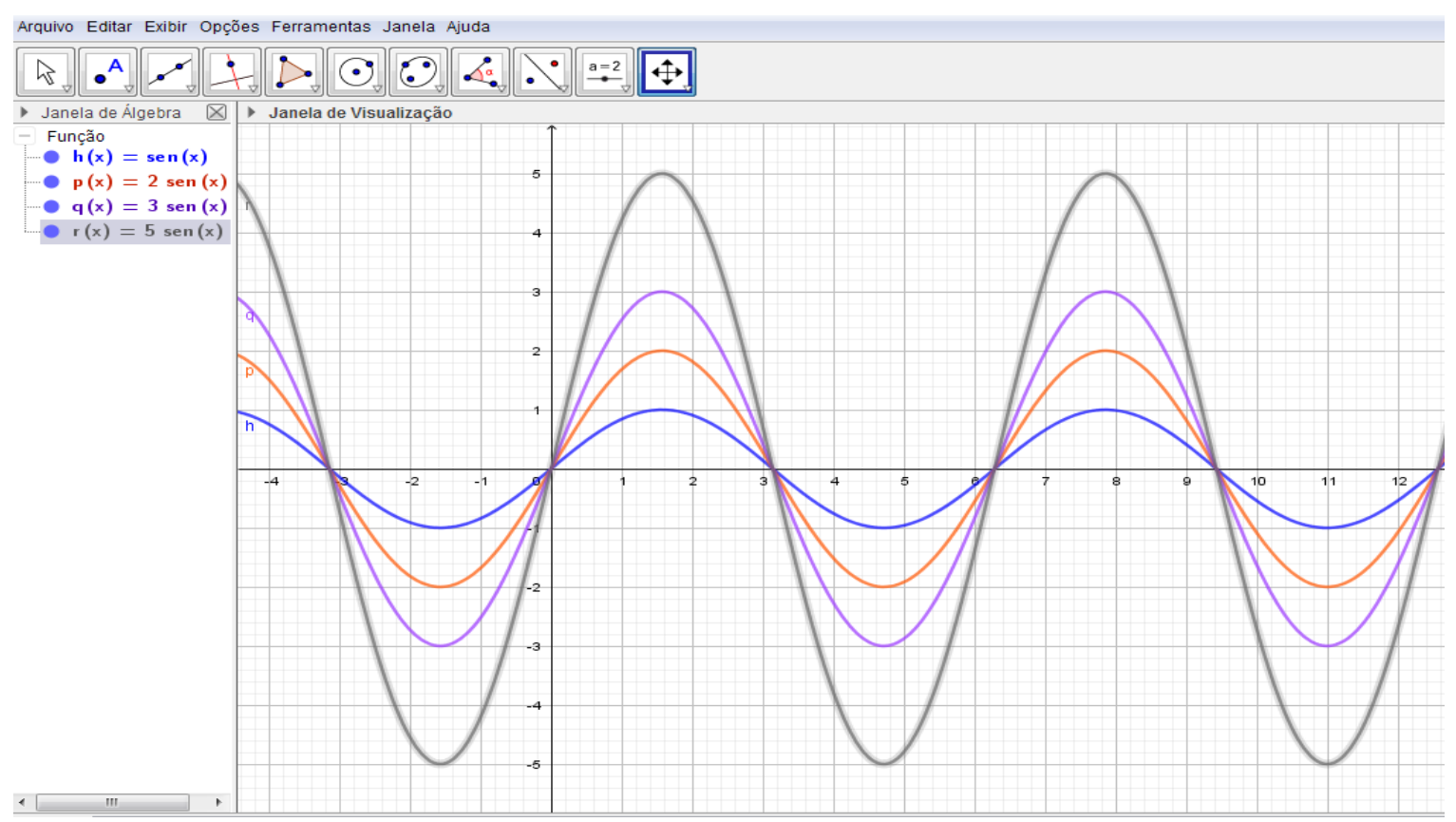

Figura 8 - Construção do gráfico das funções seno.

Fonte: Construído pelos alunos.

Nesse momento foi trabalhado a interpretação de gráficos e assuntos como período e imagem de um gráfico senóide. Realizamos as seguintes perguntas abaixo após a construção, onde cada dupla respondeu oralmente suas análises.

1) Qual o comportamento dessas funções em relação ao gráfico da função: $\boldsymbol{h}(\boldsymbol{x})=\boldsymbol{s e n} \boldsymbol{x}$ ?

2) O que você pôde perceber em relação à imagem dessas funções?

3) ocorreu alteração no período da função? ( ) sim （ ) não

Percebemos nas respostas dos alunos que eles haviam entendido o que a atividade tinha proposto, pois algumas duplas conseguiram responder rapidamente e com facilidade. Para as duplas que necessitaram de mais tempo, pedimos que analisassem e visualizassem com mais atenção, com objetivo de estimular o pensamento e desenvolver habilidades de resolução.

\section{Depoimentos da aula experimental}

A turma teve a oportunidade de aprender a manipular algumas ferramentas do Geogebra, para assim desenvolver habilidades de construir gráficos de funções, de observar e alterar períodos, analisar o conjunto imagem do seno, o que possibilitou uma maior Tangram - Revista de Educação Matemática, Dourados - MS - v.2 n. 2, pp. 102-115 (2019) 


\section{Trigonometria e suas aplicações no Geogebra: aulas experimentais com alunos do ensino médio}

interatividade e trabalho cooperativo, enfim, o aluno se tornou o agente do seu próprio conhecimento.

No final da aula, a professora selecionou três alunos (A, B e C) para darem seu depoimento sobre a aula experimental. Mas antes apresentaremos cada aluno com suas características diferentes em relação a disciplina de Matemática.

- O aluno A demonstra uma capacidade de absolver o conteúdo de forma fácil, apresentando sempre um bom rendimento nas avaliações.

- O aluno B, já demora para entender o conteúdo, mas sua dedicação e esforço faz com que procure estudar em casa para aprender o conteúdo no tempo certo, procura sempre ajudar os colegas com dificuldade no assunto.

- O aluno $\mathrm{C}$ apresenta grande dificuldade em aprendizagem matemática, o mesmo possui uma base ruim, talvez seja o motivo gerador dessas dificuldades. Esse aluno apresenta grande desinteresse pela aprendizagem matemática, não consegue entender suas aplicações e não tem interesse em buscar ou se aprofundar nos assuntos estudados.

Os depoimentos dos alunos se encontram a seguir:

O aluno A iniciou fazendo a relação do conteúdo repassado no início do ano com que acabou de vivenciar no laboratório. De acordo com ele: "Essa atividade nos fez relembrar do que já tinha aprendido, além de adicionar novas coisas, por exemplo: o estudo do gráfico do seno, foi percebido que a variação da imagem é de acordo com o coeficiente da função", falou também que "o Geogebra auxilia ao ensino de Trigonometria e é um software que você vai aprender e nunca mais vai esquecer daquele conteúdo".

O aluno B falou das aplicações da trigonometria na realidade, como diz: "as aplicações estão relacionadas ao batimento cardíaco, a sonar, terremotos que todos são emitidos por períodos e intervalos ", o aluno acrescentou falando da importância de se aprender esse conteúdo para as avaliações externas e comentou que "viu na prática como a função se comporta dependendo do tipo da função".

O aluno C falou sobre o Geogebra associar os conteúdos teóricos já estudados com a prática no laboratório, falou ainda sobre seu esquecimento de assunto de Trigonometria no momento Tangram - Revista de Educação Matemática, Dourados - MS - v.2 n. 2, pp. $102-115$ (2019) 


\section{Trigonometria e suas aplicações no Geogebra: aulas experimentais com alunos do ensino médio}

das atividades, mas com a prática foi relembrando. $\mathrm{O}$ aluno comentou sobre o que lhe chamou a atenção na prática, dizendo que: "foi o entretenimento que o software oferece e a diversidade que a tecnologia a favor da matemática pode proporcionar”. Percebeu-se que o aluno apresentava uma aparência de motivação pelo aprendizado.

A partir dos objetivos traçados, obtivemos como resultados uma evolução nos tópicos de Trigonometria, uma maior participação e interesse dos alunos pelo assunto, uma melhor compreensão dos conceitos e aplicações, gerando um resultado satisfatório e um ambiente de aprendizagem cooperativa.

\section{Considerações finais}

Esse trabalho proporcionou um rico aprendizado de como ensinar Matemática, em particular o conteúdo de Trigonometria, usando os recursos tecnológicos que já estão inseridos na realidade dos alunos. Teve-se também, a oportunidade de desmistificar a ideia que o assunto de Trigonometria é difícil e que só os alunos mais talentosos conseguem aprender.

Assim, a experiência foi fundamental para adquirir e ampliar técnicas de transmissão de conteúdo, desenvolvendo habilidades que exigem mais do que uma aula tradicional de Matemática, e sim uma aula que chame a atenção do aluno e apresente suas aplicações.

Observamos que o software Geogebra contribuiu em uma melhor articulação do raciocínio lógico matemática na busca das soluções das atividades propostas, se tornando de acordo com Maia e Pereira (2015) um articulador entre a teoria e prática.

Ainda existem muitos desafios a serem enfrentados para o ensino e aprendizagem de Trigonometria, mas as aulas experimentais possibilitaram avanços significativos para o desenvolvimento intelectual da turma. Não podemos esquecer que vivemos em uma sociedade em constantes mudanças e com avanços tecnológicos cada vez mais presentes, por isso faz-se necessário o uso de novas tecnologias como apoio para o ensino de Matemática.

Tangram - Revista de Educação Matemática, Dourados - MS - v.2 n. 2, pp. 102-115 (2019) 


\section{Trigonometria e suas aplicações no Geogebra: aulas experimentais com alunos do ensino médio}

\section{Referências}

ALVES, F.R.V. (2014). Técnica Computacional para o Ensino de Matemática. Revista Em Teia, 5(2).

Ministério da Educação. (2006). Orientações Curriculares do Ensino Médio. Brasília, DF: MEC/SEB.

CASTILHO, L.B. (2015). O uso da Tecnologia da Informação e Comunicação (TIC) no processo de ensino e aprendizagem em cursos superiores. (Dissertação de Mestrado) Universidade Fumec, Belo Horizonte.

COSTA, A.S.M. (2017). A utilização do Geogebra como ferramenta para o ensino de Trigonometria. (Dissertação de Mestrado) Universidade Federal do Espírito Santo, Vitória.

COSTA, W.R.J. \& SOUZA, F.S. (2018). O Software GeoGebra e a Construção do Conceito das Relações Seno, Cosseno e Tangente. Educação Matemática em Revista, 34, p. 32-43.

LISBOA, P. (2013). Os softwares educativos e a construção de habilidades cognitivas na pré-escola. Revista Práticas de Linguagem. 3(1). Recuperado em:< http://www.ufjf.br/praticasdelinguagem/files/2013/07/13-22-OS-SOFTWARESEDUCATIVOS-E-A-CONSTRU\%C3\%87\%C3\%830-DE-HABILIDADESCOGNITIVAS-NA-PR\%C3\%89-ESCOLA.pdf>.

LOPES, M.M. (2018). Contribuições do software GeoGebra no ensino e aprendizagem de Trigonometria. XIII Conferência Interamericana de Educação Matemática. Recife. Recuperado em:< http://ppgecm.ensinodeciencias.net/produtos/lydianne/pdf/T12.pdf>.

MAIA, J.M. \& PEREIRA, M.G.P. (2015). O Software GeoGebra: Uma Estratégia de Aprendizagem Aplicada no Estudo de Funções Trigonométricas. Ciência e Natura, 37 , p. 401-410. Recuperado em< http://oaji.net/articles/2017/16021486724136.pdf>.

PACHECO, J.A.D. \& BARROS, J.V. (2013). O Uso de Softwares Educativos no Ensino de Matemática. Revista Diálogos, 8, p. 5-13. Recuperado em:< http://www.revistadialogos.com.br/dialogos_8/adson_janaina.pdf $>$.

Tangram - Revista de Educação Matemática, Dourados - MS - v.2 n. 2, pp. 102-115 (2019) 
Trigonometria e suas aplicações no Geogebra: aulas experimentais com alunos do ensino médio

TOLEDO, B.S. (2015). O Uso de softwares como ferramenta de ensino-aprendizagem na educação do ensino médio/técnico no Instituto Federal de Minas Gerais. (Dissertação de Mestrado Profissional). Universidade FUMEC, Belo Horizonte.

Enviado:24/06/2018

Aceito:10/11/2018

Tangram - Revista de Educação Matemática, Dourados - MS - v.2 n. 2, pp. 102-115 (2019) 